\title{
LOS ALARIFES DE LA CIUDAD EN LIMA DURANTE EL SIGLO XVII
}

\author{
POR ANTONIo SAN CRistóbal
}

Con los fondos municipales de la ciudad de Lima se analiza la mayectoria de los principales alarifes o maestros de albañilería durante el siglo XVII, así como las normas por las que se regían, y las labores que realizaban. En cuadros finales aparecen reseñados todos ellos durante los años en que ejercieron su oficio.

Using the documentary evidence of the city of Lima, this paper analyses the careers of the main alarifes, or master builders, during the 17 th century, as well as the regulations affecting them and the duties they performed. They are all featured in charts at the end of the article, covering the years in which they worked.

\section{EL CARGO DE ALARIFE DE LA CIUDAD}

Empleamos ahora la terminología de alarifes de la ciudad en un sentido más restringido que el término general de alarife atribuido a los maestros de albañilería que trabajaron en Lima durante el período virreinal. Cada año, en la sesión del Cabildo siguiente a la de la elección de los alcaldes, los capitulares elegían a principios del mes de enero un reducido número de alarifes entre los maestros de la ciudad para que se ocuparan de los asuntos concermientes a las obras públicas. Por lo general elegían dos o tres, y en algunos casos hasta cuatro alarifes; y sólo en 1694 y 1695 sobrepasaron el número clauso.

Se trataba, pues, de un cargo público que, si bien no parece haber tenido asignado algún salario pagado de los bienes y rentas del Cabildo, otorgaba a los elegidos cierta preeminencia ante los restantes maestros del oficio, y también implicaba un reconocimiento público de competencia profesional. 
No era función de los alarifes de la ciudad la de ejecutar las obras públicas por encargo del Cabildo, ya que ellas se sacaban a "remate" o licitación mediante los correspondientes pregones dados por el pregonero en "altas y grandes voces". Los alarifes de la ciudad emitían "pareceres" o dictámenes acerca de los asuntos que les encomendaban los regidores; acompañaban a los comisarios en "la vista de ojos" a algunas obras controvertidas o a los tajamares del río necesitados de constantes reparaciones así como a las cañerías del agua de beber; y proponían los reparos que se habían de hacer en los edificios de la ciudad. Ni la precariedad del nombramiento anual, aunque renovable en el siguiente mes de enero, ni las tareas burocráticas y periciales que desempeñaban, permiten vislumbrar alguna influencia decisiva y preponderante ejercida por los alarifes de la ciudad en lo concerniente al desarrollo urbano y arquitectónico de la ciudad de Lima, en virtud del cargo edilicio. El encargo oficial de alarife de la ciudad era compatible con el ejercicio de la actividad profesional de los nombrados en cuanto maestros de albañilería con la que mantenían sus familias. La tarea del progreso arquitectónico de la ciudad, que no estaba a su alcance realizar en cuanto funcionarios nombrados por el Cabildo, la cumplieron holgadamente como profesionales particulares de la albañilería.

Poco aportaría para ampliar el conocimiento de la arquitectura virreinal limeña del siglo XVII la sola relación de los alarifes de la ciudad. No obstante, la lista de los alarifes reporta ciertas ventajas, ya que mediante ella adquirimos noticias de gran número de alarifes activos en Lima durante el siglo XVII, y de los términos cronológicos entre los que ejercieron el oficio de la albañilería. Estas informaciones básicas ayudarán a formular una historia más abarcadora, más densa y más precisa de la arquitectura virreinal limeña que la que ofrecen los tratadistas clásicos. Como hemos reiterado en otras oportunidades, la información que se ha venido usando por los historiadores estaba limitada a la que aportaron hasta 1950 los patriarcas de la investigación de archivo: Lohmann Villena, Vargas Ugarte, Harth-Terré, Gento, Víctor Barriga, etc. A esas informaciones se remitió explícitamente Wethey; y, sin embargo de ello, sólo logró mencionar en el apartado que dedica a los artistas los siguientes nombres para el siglo XVII limeño: Juan Martínez de Arrona, Pedro de Noguera, Andrés de Espinosa, Juan de Aldana y don Constantino de Vasconcelos, además de los religiosos Martín de Aizpitarte, Fray Pedro Galeano, Fray Cristóbal Caballero, Fray Gerónimo de Villegas, y Fray Miguel de Huerta ' . Aunque añade todavía otros escasos nombres al ofrecer la descripción de los monumentos limeños más importantes, la relación de los alarifes por él conocidos resulta tan restringida

1. H.E. WETHEY, Colonial architecture and sculpture in Perú, Harvard Uni. Press., Cambridge, Massachusetts, 1949, págs. 6-8. 
que parece muy poca cosa por cierto en relación al gran número de las construcciones y restauraciones realizadas en Lima durante todo el siglo XVII. La conocida obra de Bernales Ballesteros Lima, la ciudad y sus monumentos, depende lo mismo que la obra de Wethey, de la documentación conocida hasta 1950; y, consiguientemente, apenas incorpora esporádicamente el nombre de algún que otro alarife al parco repertorio que manejaba Wethey ${ }^{2}$.

A la luz de estos estudios clásicos podrá inferirse que gran parte de la arquitectura virreinal limeña se encontraba constreñida a permanecer en el anonimato. Siempre hemos considerado que las informaciones de los partiarcas constituyen el punto de partida de una tarea de grandes alientos y proyecciones que se ofrecía por cumplir; y que no podía quedar estancada como un término inflanqueable más allá del cual no podría progresarse. La relación cronología de los alarifes de la ciudad constituye también un estímulo incitador para cumplir otras investigaciones complementarias, entre ellas las siguientes: primera, la tarea de ampliar los plazos cronológicos en los que se desenvolvió la actividad profesional de los alarifes, ya que con la excepción del maestro de cañerías Pedro Fernández de Valdéz y la de Juan de Mansilla, no coincidieron los plazos del nombramiento y los de la actividad profesional particular. Segunda, la de conocer las obras construidas o reconstruidas por los alarifes elegidos por el Cabildo, no precisamente en virtud del cargo oficial, sino como artífices particulares. Tercera, la de completar la relación con los nombres y las obras de los maestros de albañilería activos igualmente en Lima, pero que no fueron honrados por el Cabildo, Justicia y Regimiento con la elección de alarifes de la Ciudad de los Reyes del Perú.

Adoptaron los regidores de la ciudad un doble procedimiento para designar cada año a los alarifes de la ciudad. Durante algún tiempo, especialmente en el primer tercio del siglo XVII, recurrieron a la votación secreta mediante papeletas de escrutinio; posteriormente, prefirieron el sistema más rápido de la designación directa, que en muchos casos se repetía de unos años a otros. Las actas de los Libros de Cabildos reiteran insistentemente en la elección de cada año la exigencia de que los nombrados deberían estar examinados en la profesión; pero resulta que los regidores no mostraron nunca la voluntad eficaz de hacer cumplir sus propios requisitos establecidos por ellos mismos. En la designación de los artífices Antonio Mayordomo y Domingo Cabezas, realizada el día 5 de enero de 1623 , constataron los regidores que los elegidos no estaban examinados, lo cual no fue obstáculo para que dejaran de ratificar la elección, aunque con el voto en contra de dos regidores partidarios del cumplimiento estricto del requisito del examen previo. Argumentaba la mayoría que esas personas habían sido elegidas

2. J. BERNALES BALLESTEROS, Lima, la ciudad y sus monumentos, Sevilla, 1972. 
en años anteriores; y todavía más, los volvieron a designar en años posteriores sin necesidad de que precediera el examen. Tampoco consta en los Libros de Cabildos que los alarifes cumplieran con hacer el juramento del cargo que se solía exigir en otras elecciones.

El cargo de alarife de la ciudad no interfirió en nada con el de maestro mayor de fábricas. Mientras que el Cabildo asignaba ritualmente a comienzos de cada año los alarifes de la ciudad, sólo aparece que se ocuparon del cargo de maestro mayor de fábricas en tres ocasiones distintas y discontinuas. En la sesión del día 4 de enero de 1610 otorgaron el cargo de maestro mayor de fábricas al alarife Juan del Corral que se ocupaba entonces de la construcción del puente de piedra sobre el río; a su vez, este maestro propuso los nombres de "las personas maestros de albañiles que hay en esta ciudad muy prácticas y expertos para ser alarifes de ella" 3; los que fueron nombrados por el Cabildo.

A la muerte de Juan del Corral quedó vacante el cargo de maestro mayor de fábricas, sin que ni el Virrey ni tampoco el Cabildo de la ciudad volvieran a ocuparse de proveerlo, acaso porque no se construyeron otras obras públicas importantes como la del puente que requiriera los servicios de otro maestro mayor de fábricas. El ensamblador Pedro de Noguera logró después de terca insistencia que el Cabildo le reconociera el título de "maestro escultor y arquitecto mayor", que le había conferido el propio Virrey; pero el Cabildo introdujo las condiciones de que no recibiría salario alguno por el ejercicio de tal título, y que además tampoco llevaría aparejada preeminencia alguna sobre los alarifes de la ciudad, cuando se escuchaban sus pareceres. Usó Noguera ese cargo hasta su muerte acaecida en febrero de 1656. A los pocos días de muerto Noguera, el Cabildo propuso a la aprobación del Virrey el nombramiento de Fray Diego Maroto para el cargo "tal y como lo tenía Noguera". Pero como el dominico Maroto no era escultor, ni tampoco arquitecto o ensamblador de retablos, sino maestro de albañilería, al pasar el título a sus manos perdió este por desuso la calificación oficial que tenía y con la que se había otorgado a Pedro de Noguera, y se transformó espontáneamente en la denominación de maestro mayor de fábricas: con este nombre usó Maroto de tal título hasta su muerte acaecida a finales de 1696 o principios de 1697; pero nunca recibió salario oficial por razón del título.

Rigió de hecho una clara delimitación entre el título de maestro mayor de fábricas y el nombramiento de alarifes de la ciudad. El maestro Juan del Corral sólo recibió el título de maestro mayor, pero no el de alarife de la ciudad. El

3. Arch. His. de las Municipalidad de Lima (AHML), Libros de Cabildo, libro 15, 1610, folio 7vta. Citamos siempre por los Libros de Cabildos originales, no por los editados que tienen otra numeración. 
ensamblador Noguera fue nombrado alarife de la ciudad únicamente en 1645, 1646 y 1647; y Fray Diego Maroto recibió el nombramiento de alarife tan sólo el año de 1685 por la extraña circunstancia de elegir ese año como alarifes a todos los que habían sido designados medidores de tierras por el Cabildo. Ambas funciones eran distintas; y así Noguera fue nombrado medidor de tierras desde 1634 hasta 1655, con algunas interferencias; y Fray Diego Maroto fue nombrado ininterrumpidamente en este segundo cargo desde 1666 hasta 1696.

\section{LOS MAESTROS DE ALBAÑILERÍA Y LOS ALARIFES DE LA CIUDAD}

Si analizamos la relación de los alarifes nombrados durante el siglo XVII, comprobaremos que mientras algunos maestros fueron designados durante un cierto número de años consecutivos o alternados, otros aparecen con muy poca frecuencia en un sólo año. Naturalmente, que el ejercicio de la actividad profesional como albañiles de estos últimos no fue tan corto como el nombramiento efectuado por el Cabildo.

En algunos casos, la no reiteración del nombramiento pudo expresar la irrelevancia de sus trabajos como constructor de obras. El día 7 de enero de 1611 el Cabildo nombró junto con otros alarifes de conocida trayectoria profesional en la ciudad a un tal Juan Pérez ${ }^{4}$. No he encontrado anotado en mi registro de alarifes de Lima ningún trabajo suyo; y tampoco volvió a ser elegido para el mismo cargo. El albañil Antonio Nolete aparece como alarife de la ciudad para el año de $1694^{5}$. Se realizó este año el nombramiento más numeroso de alarifes; y por ello aparece designado entre ellos el albañil Nolete que tuvo una actividad limitada a dos o tres años. También aparece como alarife de la ciudad por única vez en 1694 el maestro Francisco Jiménez de Molina; sin embargo, según mis registros, trabajó activamente en Lima desde el 7 de octubre de 1677 hasta el 11 de enero de 1701, y cumplió obras importantes en el Convento e Iglesia de San Agustín, en el local de la Real Universidad de San Marcos, en el Colegio Real de San Felipe y además levantó 3.000 varas de la muralla de Lima. Junto con los últimos mencionados, figura como alarife de la ciudad por los años de 1694 y 1695 un tal Sedillo o Cedillo, primero con el nombre de Diego, y luego con el de Alonso, acerca del cual tampoco he logrado acopiar información alguna referente a las obras que hubiera realizado.

4. A.H.M.L., Libros de Cabildo, libro 15, 1610, folio $138 \mathrm{vta}$.

5. A.H.M.L., Libros de Cabildo, libro 32, 1689, folio 125. 
Forman un pequeño grupo algunos maestros que ejercieron el cargo de alarifes por pocos años. Así encontramos a Adrián Troche en 1631 y 1636; Pedro Benítez en 1647 y 1649; Miguel de Garáy en 1661; Mateo de Olivera en 1664; Juan Durán Velo en 1693 y 1694 . Todos ellos accedieron a la función pública de alarifes con el respaldo de algunos años en el ejercicio de la profesión como maestros de albañilería. Tenemos registradas en nuestro fichero de alarifes obras de estos maestros por los siguientes años: Adrián Troche desde el 4 de mayo de 1631 hasta el 27 de julio de 1640; Alonso Benítez desde el 1 de octubre de 1641 hasta el 8 de octubre de 1649; Miguel de Garay trabajó desde el 27 de marzo de 1656 hasta el 6 de mayo de 1695, y anteriormente había trabajado en las murallas del puerto del Callao; Mateo de Olivera, desde el 11 de junio de 1645 hasta el 25 de mayo de 1680; Juan Durán Velo, desde el 17 de agosto de 1684 hasta el 29 de diciembre de 1695. Es posible que además ejecutaran otras obras antes y después de los términos señalados, que no están registradas en mi archivo de alarifes. Nos interesa resaltar que estos cinco artesanos fueron eficientes constructores de casas de vivienda, celdas para monjas en los monasterios, y otros edificios de uso civil; pero no realizaron obras ornamentales, ni tampoco intervinieron en grandes obras como capillas, iglesias, campanarios, claustros o dependencias conventuales, en las que adquiría especial relieve la arquitectura ornamental limeña, y en las que se expresaban los estilos arquitectónicos. La construcción de casas de morada evolucionó gradualmente durante todo el siglo XVII; de tal modo que existieron sin duda diferencias en la tipología de las viviendas desde el tiempo de Adrián Troche hasta el de Juan Durán Velo. Este tipo de arquitectura utilitaria y funcional puede ser estudiada en los conciertos notariales de obra firmados por estos alarifes, ya que suelen incluir la memoria descriptiva de las condiciones y especificaciones por las que debía regirse la construcción.

Podemos integrar en otro grupo a un cierto número de alarifes que ocuparon el cargo por designación del Cabildo durante unos pocos años, pero que, no obstante esa notoria postergación o marginación, ejercieron influencia decisiva para la evolución de la arquitectura virreinal limeñal. El alarife Andrés de Espinosa fue designado discontinuamente durante los años 1601, 1603, 1608 y 1616; el alarife Alonso de Arenas recibió el encargo oficial en los años de 1604, 1621 y 1622; y el portugués Domingo Alonso en 1666, 1667, 1668 y 1669 año en que murió. Sabemos que las obras realizadas por todos estos alarifes transcienden a la corta duración discontinua de su elección como alarifes. En efecto, Andrés de Espinosa trabajó en Lima desde finales del siglo XVI hasta 1621 en que por concierto firmado el día 27 de enero con el Deán y Cabildo de la Catedral de Arequipa abandonó el concierto notarial de obra que tenía firmado con el Convento de La Merced de Lima para terminar la iglesia mercedaria, y se marchó a Arequipa para construir aquella Catedral. Además de la reconversión de la iglesia de La Merced por la que introdujo en ella el crucero interno con naves 
laterales abiertas, propio de la planta basilical, Andrés de Espinosa levantó la capilla de Ntra. Sra. de Aranzazu en la vieja iglesia de San Francisco y construyó las bóvedas sepulcrales de la Cofradía de los Vascongados que todavía se conservan en el subsuelo de San Francisco; trabajó en la construcción de la Catedral de Lima hasta dejar levantadas las cimbras para las bóvedas, pero Francisco Becerra desbarató sus trabajos, aunque después de 1609 el mismo Andrés de Espinosa contribuyó a deshacer los planes de Becerra. El maestro Alonso de Arenas fue maestro mayor de la Catedral de Lima antes de Juan Martínez de Arrona; levantó el cuerpo y las bóvedas de la iglesia del colegio agustiniano de San Ildefonso; comenzó pero no terminó las bóvedas de la iglesia del Monasterio de la Santísima Trinidad; hizo un claustro en la Recoleta dominicana de La Magdalena; construyó la capilla mayor y las colaterales en la iglesia de la Recoleta mercedaria de Belén con sus bóvedas; acudió a fabricar la capilla mayor y las bóvedas de la iglesia franciscana de Huánuco; y junto con Andrés de Espinosa emprendió la reconversión de la planta en la iglesia de La Merced de Lima. El maestro Domingo Alonso trabajó en Lima, al menos, desde el 22 de agosto de 1646 hasta su muerte a finales de 1669. Realizó Domingo Alonso numerosas obras: a la muerte del maestro Miguel Rodríguez, construyó la segunda iglesia del Monasterio de Santa Clara; levantó la portada de la iglesia del Monasterio de La Limpia Concepción; hizo la capilla de la Vera Cruz en el convento de Santo Domingo; cubrió la bóveda vaída lisa sobre la capilla mayor de la iglesia de Ntra. Sra. del Prado; hizo la capilla mayor de la iglesia de Ntra. Sra. de Guadalupe; tuvo a su cargo el patio del Colegio de Gramática de San Pablo de los jesuítas; ejecutó el santuario sobre el coro en el Monasterio de la Santísima Trinidad según planta de Fray Diego Maroto; fabricó la segunda portada de la iglesia de la Limpia Concepción y la del Monasterio. Es posible que las múltiples ocupaciones profesionales de estos importantes alarifes, además de las numerosas casas y celdas por ellos construidos, no les dejaran tiempo libre para atender los pequeños asuntos de las obras municipales en las cañerías de agua de beber, las alcantarillas y los tajamares del río.

A diferencia de estos tres influyentes maestros, el modesto artesano Domingo Cabezas fue elegido alarife de la ciudad en los años de 1622, 1623, 1624, 1625,1628 y 1629 . Había trabajado Cabezas en Lima durante los años desde 1621 hasta 1631; un período de actividad profesional mucho más corto, por ejemplo, que el de Miguel de Garáy que durante sus 40 años de trabajos documentados sólo fue elegido alarife un sólo año. El albañil Domingo Cabezas actuaba en este oficio y también como cantero: además de tallar unas piedras y escudos para la antigua pila de la plaza pública, y para la portada del Perdón en la Catedral, realizó pequeños trabajos en el alcantarillado de la ciudad, y algunas pequeñas portadas en una casa más abajo de La Merced. 
Prevalecieron ampliamente en el ejercicio del cargo de alarifes de la ciudad los maestros de cañerías; pues no en vano esta era una de sus principales ocupaciones. Desde 1620 hasta su muerte en 1634 aparece nombrado en el cargo el maestro Clemente de Mansilla; y poco tiempo después le sucedió su hijo Juan de Mansilla que estuvo nombrado desde 1641 hasta 1665; el más estable de todo el siglo XVII fue el maestro Pedro Fernández de Valdés que comenzó como alarife de la ciudad en 1650 y desde entonces permaneció en funciones al menos hasta 1701 casi ininterrumpidamente. Los primeros años le denominan Hernández; luego Fernández; y finalmente con el apellido completo de Fernández de Valdés. El arreglo de las cañerías y el de los tajamares del río reaparecen continuamente en las actas de los Cabildos de Lima durante todo el siglo XVII.

Desde 1664 hasta 1670 designaron los regidores de la ciudad junto con los alarifes para las obras de albañilería, al maestro de carpintería Pedro de Céspedes para las obras de carpintería. Tengo registradas obras de este maestro desde el 3 de marzo de 1638 hasta el 27 de septiembre de 1676. Las viviendas de Lima se cubrieron durante la época virreinal con techumbres planas de madera; por tal motivo desempeñaron los carpinteros una tarea complementaria de la de los albañiles en la arquitectura de obra civil; además de la que cumplieron los carpinteros mudéjares hasta mediados del siglo XVII en la construcción de las armaduras de madera de cinco y hasta de siete paños para cubrir el cuerpo de las viejas iglesias gótico-isabelinas. De todos modos, el carpintero Pedro de Céspedes fue el único maestro de esta especialidad nombrado como alarife de la ciudad; pues ni antes ni después de él volvió el Cabildo a nombrar alarifes para las obras de carpintería.

Como se ha indicado antes, no todos los alarifes y maestros de albañilería activos en Lima durante el siglo XVII alcanzaron el nombramiento de alarifes de la ciudad. Para completar el conocimiento histórico de la arquitectura virreinal limeña hay que considerar también a los albañiles no designados por el Cabildo para el cargo oficial.

A pesar de que el Cabildo no eligió nunca como alarife al maestro Juan Martínez de Arrona, no por eso dejó de recurrir a su experiencia profesional en asuntos que competían a los alarifes nombrados. El 12 de mayo de 1628 los Comisarios del Cabildo le encomendaron la tasación y transación con la Hermandad de la cárcel pública acerca de la propiedad de una azotea: cumplió Juan Martínez de Arrona este trabajo en compañía de Clemente de Mansilla que había sido nombrado alarife ${ }^{6}$. Los Comisarios llevaron a Martínez de Arrona el día 3 de agosto de 1629 a reconocer los tajamares del río aderezados por Miguel Izquierdo y que mostraban deficiencias en la ejecución de los reparos ${ }^{7}$ : esta era

6. A.H.M.L., Libros de Cabildo, libro 20, 1628, folio 39 vta.

7. Ibid., folio 133 vta. 
una de las funciones que competían a los alarifes nombrados: el 14 de septiembre de 1629 emitió ante el Cabildo parecer acerca de la cañería de agua de beber solicitada por el Convento de Señor San Agustín ${ }^{8}$; y el 30 de septiembre de 1630 taś6 junto con el alarife nombrado Clemente de Mansilla los reparos y las tallas que labró Domingo Cabezas para la pila de la plaza pública de la ciudad ${ }^{9}$.

Otros numerosos artesanos de la albañilería, además de los nombrados por el Cabildo como alarifes de la ciudad trabajaron en Lima durante el siglo XVII. Muchos de ellos sólo dejaron registrada en los protocolos notariales o en los libros de cuentas de los Monasterios y Cofradías alguna que otra obra de casas de vivienda, celdas, $o$ aderezos de cañerías, tajamares o alcantarillas. Consignamos ahora aquellos artesanos de los que tenemos registradas en el archivo de alarifes las construcciones realizadas por ellos durante un período más prolongado, dejando de lado los artesanos que sólo trabajaron esporádicamente.

De Domingo de Aguilar tengo registrados trabajos desde 1655 hasta 1666; de Lorenzo de Aramburú desde 1666 hasta 1671; de Diego de la Gama desde 1648 hasta 1666; de Lorenzo de los Ríos desde 1659 hasta 1677; de Francisco Díaz desde 1634 hasta 1654; de Francisco Javier Domínguez desde 1676 hasta 1685; de Miguel Izquierdo desde 1615 hasta 1639; de Juan Martínez de Arrona desde principios del siglo XVII hasta su muerte en enero de 1635; de Diego de Mondragón desde 1654 hasta 1683; de Miguel Rodríguez desde 1636 hasta 1645; de Juan Rodríguez Montañéz desde 1639 hasta 1642; de Julián Sánchez desde 1646 hasta 1664; de Francisco de Sierra desde 1666 en que comenzó su aprendizaje del oficio de albañil hasta finales del siglo XVII y también en el siglo XVIII.

Puede aceptarse que la mayor parte de estos maestros no fueron artesanos de primera línea; pero en parte realizaron obras diseñadas por alarifes tan destacados como Fray Diego Maroto; y en parte completan el repertorio de los maestros activos durante el siglo XVII en Lima. Se ha de tener también en cuenta que algunos de los maestros nombrados como alarifes por el Cabildo de la ciudad tampoco alcanzaron un nivel profesional superior al de los albañiles que no fueron designados como alarifes.

No se incluye en esta relación de maestros de albañilería al albañil Diego Pérez de Guzmán, a causa de los problemas históricos suscitados acerca de sus trabajos. Influenciados por una versión deformada de Vargas Ugarte, los historiadores confirieron a este albañil gratuitamente el título de "arquitecto". Resulta que en las once (11) fichas acerca de sus trabajos reunidas en mi archivo de alarifes no hay fundamento más que para reconocerle como modesto peón u
8. Ibid., folio 141 vta.
9. Ibid., folio 244 . 
oficial de albañilería. El trabajo mejor remunerado que aparece en esas fichas es el de los aderezos ejecutados en la casa de don Nicolás del Campo, por los que recibió la cantidad de 150 pesos de a ocho reales el peso ${ }^{10}$; y por hacer los remiendos en la portada de la iglesia del Monasterio de la Limpia Concepción le pagaron 120 pesos.

\section{LAS GENERACIONES DE ALARIFES DURANTE EL SIGLO XVII}

No se trata de elaborar una relación completa de todos los alarifes que trabajaron en Lima a lo largo del siglo XVII. Pretendemos sólo reunir a los más destacados alarifes y maestros de albañilería en grupos generacionales, tomando como base de agrupamiento su producción artesanal conocida por documentos históricos fehacientes, y con la determinación estricta de las fechas en que fueron realizados los trabajos. No podemos basarnos en la edad cronológica de los alarifes, como un criterio seguro para la clasificación de las generaciones, porque además de ser desconocidas en casi todos los casos, presenta otros índices de variabilidad: alarifes de una misma edad cronologica que trabajaron en distintas épocas; y en la misma época coexistieron alarifes de distintas edades cronológicas; motivado todo esto, porque gran parte de los alarifes, especialmente los de la primera mitad del siglo XVII, eran naturales de España y llegaron al Perú con intermitencia irregular.

Dificulta también la estricta adscripción de los alarifes a una generación determinada la diferencia tan acentuada entre el ciclo de la actividad profesional en unos y otros maestros: algunos gozaron de una longevidad admirable como maestros activos, tales son los casos de Pedro Fernández de Valdés, Fray Diego Maroto, Francisco de Ibarra y Miguel de Garay; mientras que otros apenas alcanzaron un corto ciclo productivo, como Joseph de la Sida, Luis Fernández Lozano y Juan Rodríguez Montañés, que, a juzgar por sus trabajos conocidos, hubieran ejercido notable influencia en la arquitectura virreinal limeña, de haber permanecido activos un tiempo más duradero.

Después de lo expuesto anteriormente, quedará claro que no asumimos como manifestación de las generaciones a los alarifes la cronología de sus nombramientos para el cargo oficial por el Cabildo de la ciudad. Baste citar que Manuel de Escobar, activos desde 1655, fue elegido alarife de la ciudad por vez primera en 1674, cuando ya había terminado la obra de la iglesia de San Francisco y también después de realizar sus obras más importantes. Lo mismo sucedió con

10. A.G.N. Archivo General de la Nación, escribano Pedro PÉREZ LANDERO, 1690, protocolo 1494 , folio 208 . 
Domingo Alonso, Fray Diego Maroto y Francisco Cano Melgarejo, nombrados muy tardíamente en relación a sus trabajos profesionales. De igual modo, tampoco limitamos los miembros de cada generación de alarifes a los que figuran en la relación de los nombrados por el Cabildo de la ciudad, ya que otros alarifes importantes no alcanzaron nunca tal nombramiento.

Tomamos como criterio de la clasificación generacional el proceso temporal de sus obras conocidas documentalmente, y determinado por las fechas de la primera obra conocida y de la última según los registros de mi archivo de alarifes limeños, en que consta la referencia documental exacta de cada obra. Es necesario aclarar que los términos asignados a cada alarife pueden ser desplazados hacia adelante y hacia atrás en los casos en que se descubran documentos hasta ahora no registrados con nuevas obras ejecutadas por ellos. De todos modos, consideramos como bastante confiable este criterio dentro de los límites señalados de acuerdo al estado actual de las investigaciones de archivo realizadas en los repositorios documentales de Lima de la época virreinal. Es un criterio flexible, que permite ser revisado tanto en el número de los componentes de cada generación, como en lo que atañe a la determinación del período activo de cada alarife.

En una obra en proceso de publicación auspiciada por el Patronato de Lima acerca de la arquitectura virreinal limeña se han analizado algunos problemas históricos como el de la caracterización estilística del período inicial de la arquitectura limeña en el siglo XVII, y el de la determinación de las etapas del barroco limeño. Se tomaron en cuenta entonces los aspectos estilísticos, estructurales y ornamentales discernibles en la arquitectura limeña. No se proyectaron hacia el primer plano de los análisis historiográficos la agrupación de los alarifes en generaciones correspondientes a los diversos períodos históricos de la arquitectura limeña, especialmente la del siglo XVII. Habrá que supèrponer ahora las generaciones de los alarifes limeños a las parcelaciones en períodos históricos y a las caracterizaciones estilísticas y estructurales de tales etapas, para llegar a conseguir una comprensión más plena de la arquitectura limeña. Hubiera sido deseable presentar junto a los nombres y a la cronología global de los alarifes limeños el repertorio de sus obras más significativas, pero este tratamiento metodológico nos llevaría a desbordar amplísimamente los datos documentales algunos centenares de fichas de archivo.

Incluimos en la primera generación de alarifes del siglo XVI aquellos maestros que trabajaron en Lima en la década final del siglo XVI y que prolongaron su actividad durante la primera década del siglo XVII: Francisco Becerra, Juan del Cerro, Pedro Falcón, Cristóbal Gómez, Pedro Blasco, y Alonso Morales; a ellos se acumuló Juan del Corral que murió en Lima poco tiempo después de haber terminado el puente de piedra. El alarife Francisco Becerra parece haber 
profesado unos cánones renacentistas más actualizados y depurados que los restantes alarifes de esta generación. El maestro mayor de fábricas Juan del Corral no tuvo tiempo para mostrar en obras ornamentales sus concepciones estilísticas. En los restantes miembros de esta primera generación prevalecieron los cánones gótico-isabelinos-mudéjares sobre los estrictamente renacentistas: aquellos lineamientos habían prevalecido en Lima durante el último tercio del siglo XVI.

Como complemento de la generación que cabalgó entre los dos siglos, distinguimos otra generación procedente de los años finales del siglo XVI, pero que extendió su actividad profesional aproximadamente hasta 1620. Estaría integrada por Alonso de Arenas, Andrés de Espinosa, Diego Guillén, Francisco Morales, Francisco Vázquez del Castillo y también Juan Martínez de Arrona. Esta generación fue la que configuró el rostro arquitectónico de Lima durante el primer tercio del siglo XVII. Al poner de manifiesto la influencia ejercida por los autores de la reorientación de la arquitectura limeña a consecuencia de los daños causados por el terremoto de 1609 en las bóvedas de la Catedral, se refuerza nuestra convicción de que los criterios renacentistas introducidos por Francisco Becerra en la Catedral fueron desbordados y anulados por las concepciones gótico-isabelinas-mudéjares más arcaicas. Ninguno de los alarifes de esta generación manifestó haber asimilado ideas estéticas renacentistas más actualizadas. En lugar de haber aportado la renovación de los cánones arquitectónicos, los miembros de esta generación reactualizaron las bóvedas de crucería gótico-isabelina y las armaduras mudéjares de madera que se emplearon en Lima desde el siglo XVI.

En algunos otros aspectos, esta generación pasó directamente desde el gótico-isabelino-mudéjar al barroco inicial, sin recalar siquiera en el manierismo; de tal modo que la arquitectura virreinal limeña no siguió la secuencia cíclica de los estilos cumplida en la arquitectura europea, pues faltó en ese proceso una etapa manierista plena. Los alarifes Andrés de Espinosa y Alonso de Arenas inauguraron el proceso de la reconversión de la planta gótico-isabelina en las grandes iglesias a la planta basilical barroca de tres naves abiertas con crucero interno dentro de un perímetro murario rectangular. El maestro Juan Martínez de Arrona supo transformar el diseño renacentista de la portada catedralicia principal del Perdón en el diseño barroco de portada-retablo de tres calles paralelas en los dos cuerpos. Comenzó, pues, al final del trabajo de esta generación la etapa en Lima del barroco parcial, aunque coexistió con formas arcaicas en las estructuras de las pequeñas iglesias gótico-isabelinas y con las cubiertas vaídas de crucería y los alfarjes mudéjares en todas las iglesias limeñas grandes y pequeñas.

Desde 1620 hasta 1640 trabajó en la arquitectura de Lima otra generación de alarifes que no tuvieron vínculos directos e inmediatos con la generación de finales del siglo XVI. Adscribimos a esta generación los siguientes alarifes: 
Domingo Cabezas, Francisco Fajardo, Luis Fernández Lozano, Clemente de Mansilla, Antonio Mayordomo, Adrián Troche, Joseph de la Sida, Miguel Izquierdo, Juan Rodríguez Montañés y Miguel Rodríguez. Fue una generación de transición, que mantuvo los cánones renacentistas y los gótico-isabelinos-mudéjares, como se observa en la pequeña iglesia limeña de Monserrate, obra de Luis Fernández Lozano, que está bastante desfigurada en su pequeña portada de los pies y con la añadidura del campanario cuadrado. Fueron obras de esta generación el cuerpo bajo de la torre del Convento de Señor San Agustín, obra iniciada por Joseph de la Sida; y la ampliación del coro alto en la iglesia del Convento de Santo Domingo realizada por Antonio Mayordomo. Los cuerpos gruesos bajos de las torres aportaron una estructura que, si bien seguía los lineamientos renacentistas de principios del siglo XVII, fueron asumidos posteriormente en el esquema barroco de la gran fachada a los pies de las iglesias.

A partir de 1640 comenzó a realizar las tareas de la construcción arquitectónica en Lima otra generación de alarifes que perduró en actividad hasta 1660. La integraron Domingo Alonso, Francisco de Ibarra, Alonso Benítez, Fray Diego Maroto, Juan de Mansilla, Pedro Miguel, Diego de la Gama, Francisco Díaz, Julián Sánchez y Pedro de Noguera en su etapa de maestro mayor de obras de la Catedral y de maestro escultor y arquitecto mayor de la ciudad. Dos de los alarifes adscritos a esta generación: Maroto y Francisco de Ibarra, gozaron de privilegiada longevidad activa, pues perduraron como alarifes en diversos trabajos hasta comienzos de la década de 1690; y supieron evolucionar en sus concepciones estilísticas y ornamentales, de tal modo que también pueden ser considerados como integrantes de la generación inmediatamente siguiente. Mediante los trabajos de esta generación, adquirió pleno impulso creador la etapa del barroco parcial limeño. Se trata de una etapa plenamente barroca en lo que atañe a sus componentes peculiares; aún cuando resultó parcial, porque no logró transformar en barroco todo el cuerpo de las iglesias. No hay que olvidar que durante esta etapa labró el carpintero Diego de Medina algunos de los mejores y más fastuosos alfarjes mudéjares de cinco y hasta de siete paños para algunas iglesias limeñas, de los que se conserva todavía el que cubre la antisacristía de la iglesia de Señor San Agustín. El cuerpo bajo de la portada de la iglesia del Monasterio de la Limpia Concepción, la portada de la iglesia de Ntra. Sra. del Prado, y la torre solitaria de la iglesia de Santo Domingo, obras todas documentadas de Fray Diego Maroto, expresan los caracteres estilísticos de este barroco parcial.

Me permito reiterar mi total discrepancia con la segunda interpretación historiográfica propuesta por Bernales Ballesteros, en la que calificó como manierista a todo el largo período limeño anterior a la inauguración de la iglesia del Convento de San Francisco. En una primera interpretación había calificado esa misma etapa como la del protobarroco. Anotemos que si no se desarrolló un 
manierismo pleno y predominante durante el primer tercio limeño del siglo XVII, como venimos sosteniendo, mucho menos puede ser calificada como manierista la generación de alarifes que trabajó en Lima entre 1640 y 1660: esta es la primera generación de innovadores barrocos en la arquitectura virreinal limeña.

La generación que actuó en Lima entre 1660 y 1680 realizó el barroco de complementación, pues sobre la nueva tipología de planta para las iglesias cerró bóvedas de medio cañón con lunetas del tipo que posteriormente caracterizó al barroco virreinal peruano. Además, nuevas tipologías de portadas comenzaron a completar las innovaciones estructurales de las plantas y de las cubiertas de las iglesias. Pertenecieron a esta generación los alarifes Francisco Cano Melgarejo, Juan de Egoaguirre, Pedro Fernández de Valdés, Miguel de Garay, Mateo de Olivera, Manuel de Escobar, Domingo de Aguilar, Lorenzo de Aramburu, Diego de Mondragón y Lorenzo de los Ríos. Permanecieron también activos e influyentes durante este período los alarifes Fray Diego Maroto y Francisco de Ibarra, que habían destacado desde la generación precedente. En aquellos años se realizó una intensa actividad constructora que cambió en gran medida el rostro arquitectónico de la Ciudad de los Reyes. Sin contar con la nueva iglesia de San Francisco, destacan el Sagrario de la Catedral, Ntra. Sra. de los Desamparados, San Juan de Dios y el claustro redondo del Colegio de Santo Tomás.

La última generación del siglo XVII cumplió su trabajo profesional desde 1680 hasta finalizar el siglo. Conformaron la generación los alarifes Pedro de Asencio, Juan Iñigo de Erazo, Francisco Jiménez de Molina, Juan Durán Velo, Francisco Javier Domínguez, y Francisco de Sierra. Continuaron activos en el ejercicio de la profesión los veteranos alarifes Fray Diego Maroto, Francisco de Ibarra, Pedro Fernández de Valdés, Manuel de Escobar y Miguel de Garay. Los maestros de albañilería Diego de Sedillo o Cedillo, y Antonio Nolete, que habían sido designados alarifes de la ciudad por el Cabildo, en los años de 1694 y 1695 , trabajaron muy poco a finales de la década de 1690; y posiblemente continuaron activos durante el siglo XVIII. El terremoto de 1687 interrumpió bruscamente el período de las nuevas construcciones de iglesias iniciado anteriormente; pues los limitados recursos económicos debieron emplearse con urgencia a financiar las reconstrucciones de la ciudad, una tarea poco brillante y nada propicia para el desarrollo de la arquitectura ornamental. Sin embargo, esta generación cumplió restauraciones tan destacadas como las de La Merced y de San Agustín, además de la de la Catedral. El ensamblador de retablos Diego de Aguirre labró en 1692 la segunda portada de la iglesia del Monasterio de las Descalzas de San Joseph, reproducida en un bello dibujo de Angrand y destruida inútilmente en las restauraciones posteriores a 1940. El mercedario Fray Cristóbal Caballero, que se encontraba en el ocaso de su vida profesional, asumió tareas de reconstructor 
tanto en su propio Convento e iglesia de La Merced, como en la Catedral y las murallas de Lima; ocupó por algún tiempo el cargo de maestro mayor de obras de la Catedral a la muerte de Fray Diego Maroto. El mercedario Caballero, que también había sido ensamblador de retablos, fue nombrado por el Cabildo de la ciudad como medidor de tierras por los años de 1697,1698 y $1699^{\prime \prime}$.

\section{LA PROCEDENCIA DE LOS ALARIFES}

Entendemos ahora la procedencia de los alarifes en el sentido amplio que denota el lugar donde recibieron su formación profesional. Por supuesto, que si por ejemplo Francisco Cano Melgarejo nació en el Valle de Conchucos en la sierra del actual departamento de Ancash, no pudo haber logrado su formación como alarife mediante el conocimiento directo y personal de la arquitectura europea. De igual modo si algún alarife nacido en España llegó al Perú siendo muy joven, tampoco estuvo en condiciones de haber logrado una formación profesional arquitectónica muy amplia y versada en la arquitectura española, y sólo aplicó en sus obras limeñas lo que aprendió en el Perú. Es posible que Francisco de Ibarra y Miguel de Garay correspondan a esta segunda situación profesional.

La procedencia de los alarifes muestra directamente un dato biográfico de las personas; pero tiene también incidencias para determinar las influencias estilísticas que debieran haber llegado a la arquitectura virreinal limeña, y a la peruana en general. Cabe suponer que los alarifes sirvieron como portadores personales de tales influencias recibidas por ellos durante su formación profesional en los lugares donde iniciaron su aprendizaje del arte de la albañilería.

El tema de las transmisiones de influencias estilísticas sobre la arquitectura virreinal ha sido tratado desde diversas tendencias, pero siempre bajo un punto de vista estrictamente estilística y morfológico: ciertos caracteres dados en la arquitectura virreinal habrían sido recibidos, según estas interpretaciones historiográficas, por presuntas transmisiones de otras características similares creadas en los centros europeos primarios. Las tesis del hispanismo y del europeísmo son otras tantas formulaciones de este planteamiento teorético, aunque de signo antagónico.

No debemos soslayar que estas versiones historiográficas, de signo divergente en cuanto a la procedencia de las transmisiones externas, concuerdan en la presuposición implícita y no demostrada de que las arquitecturas virreinales, por ser tales, fueron incapaces a lo largo de todo su decurso histórico de crear sus

11. A.H.M.L., Libros de Cabildo, libro 33, 1696, folios 32 y 87. 
modelos arquitectónicos; y por ello debieron estar sometidas a la constante transmisión de influencias externas desde los centros europeos primarios no sólo en las etapas iniciales, sino incluso durante todo el siglo XVII y el XVIII. De haber podido crear autónomamente sus propias versiones estilísticas se habrían hecho innecesarias las transmisiones externas. Por otro lado, las tesis historiográficas se mantienen en un nivel de irrealidad y misticismo, pues afirman que llegaron a la arquitectura virreinal algunas transmisiones externas españolas o europeas no ibéricas; pero en ningún momento han precisado qué alarifes actuaron como portadores personales de esas presuntas transmisiones. No vamos a suponer que ellas llegaron por sí solas.

La tesis historiográfica de los aportes europeos no ibéricos ha incidido en la presencia determinante de los religiosos procedentes de otros países europeos no ibéricos como un factor que explicaría la diferencia arquitectónica entre las regiones hispanoamericanas. Destacando que "la proporción de religiosos flamencos, bárbaros, bohemios, italianos, etc., que llegaron al Sur es mayor que la de los que se dirigen hacia México", concluía Gasparini que "esta variedad de contactos y aportes culturales es posiblemente una de las causas que mejor explican las diferencias entre la arquitectura del Sur de América y de la Nueva España" ${ }^{2}$.

Nos interesa ahora iniciar el análisis de la procedencia de los alarifes virreinales, no en general y para todas las regiones de América del Sur, sino en concreto y específicamente para la arquitectura virreinal de Lima durante el siglo XVII, que es el período reconocido como el decisivo para su formación como arquitectura específica. No se prejuzga para nada cual haya sido la situación en otras regiones hispanoamericanas, como la de Quito, Bogotá, Chile, Paraguay, el Río de la Plata, etc. Tratamos sólo de la arquitectura virreinal de Lima que ofrecía a finales del siglo XVII una innegable especificidad que la constituyó en escuela regional específica. No se trata ahora de reiterar análisis morfológicos o estructurales sobre esta arquitectura concreta; sino de referimos a los alarifes que la realizaron. Conociendo los nombres y las obras de quienes actuaron en Lima como alarifes durante el siglo XVII, resalta la importancia de investigar su procedencia para precisar mejor las eventuales transmisiones externas recaídas sobre la arquitectura virreinal limeña en este período.

Por lo que antañe a la presunta afluencia a Lima de religiosos europeos no ibéricos, que hubieran sido transmisores de aportès europeos no ibéricos, podemos recurrir en primer lugar a la obra clásica de Vargas Ugarte, Ensayo de un diccionario, como fuente de informaciones, aunque sean sin citas documentales.

12. G. GASPARINI, América, barroco y arquitectura, Ernesto Armitano, editor, Caracas, 1972, pág. 179. 
Pues bien, no señala Vargas Ugarte durante todo el siglo XVII la presencia activa como alarifes o vinculados con la arquitectura virreinal limeña de un sólo religioso europeo no ibérico, al que el mismo Vargas Ugarte atribuya vinculación alguna con obras de construcción o reconstrucción. Esta ausencia es muy significativa, porque Vargas Ugarte es fácilmente proclive a transformar en arquitectos a los religiosos que participaron en obras.

La otra fuente de informaciones es mi propio archivo de alarifes limeños del siglo XVII con más de mil setecientas fichas (1.700) con la anotación exacta y precisa de la fuente documental de archivo acerca de conciertos notariales de obra, remates $o$ adjudicaciones de las obras, cartas de pago, tasaciones, pareceres o peritajes acerca de las demasías introducidas por los alarifes en las obras, etc. Los resultados que acerca del problema he podido constatar son los siguientes: $1 .$. no aparece ningún religioso europeo no ibérico que haya contratado como alarife alguna obra en Lima durante el siglo XVII; en cambio, aparecen otros religiosos distintos de la clase que suponía Gasparini. 2. no aparece ningún religioso europeo no ibérico que haya encargado a los alarifes locales cualquier clase de obra, sea como administrador, síndico de rentas y bienes de los Monasterios, mayordomos, capellanes de las cofradías, superior de los religiosos, etc. 3..$^{\circ}$ en los conciertos notariales de obra se suele añadir la exigencia de que la obra debería quedar a satisfacción de dos o más personas peritas en el arte; pues bien, es el caso que ni una sola vez aparece mencionado algún religioso europeo no ibérico a cuya satisfacción tendría que quedar alguna obra concertada con los alarifes locales.

Deducimos que a la luz de estos análisis, hasta el momento y según las informaciones disponibles, no se ha detectado la presencia activa en la arquitectura de Lima durante el siglo XVII de alguno o algunos religiosos europeos no ibéricos, ni siquiera entre los jesuítas. La ausencia de religiosos europeos no ibéricos en la arquitectura limeña del siglo XVII es total y completa en todas las etapas y en todas las manifestaciones arquitectónicas: en el renacimiento, en el barroco parcial, o en el barroco de complementación. Ningún religioso europeo no ibérico dirigió, construyó, diseñó o emitió parecer acerca de las obras realizadas por los alarifes de todas las generaciones mencionadas en el apartado precedente; y por consiguiente, no restringió en nada la plenísima libertad creadora de los alarifes locales.

En la alternativa de atribuir la especificidad de la arquitectura virreinal limeña del siglo XVII a unos hipotéticos y presuntos religiosos europeos no ibéricos, cuya presencia en Lima no ha sido detectada con nombres, fechas y obras; o la alternativa de atribuir esa misma arquitectura a los numerosos alarifes de procedencia distinta de la europea no ibérica debidamente conocidos por documentos fehacientes, y que trabajaron en la Ciudad de los Reyes del Perú; nos parece 
como única tesis plausible la segunda alternativa; pues la primera es sólo una hipótesis idealista y apriorista desprovista de toda base documental, al menos en lo que se refiere a la arquitectura limeña del siglo XVII.

Es importante notar que si, de acuerdo a la tesis europeista de Gasparini, la presencia de los religiosos europeos no ibéricos influyentes sobre la arquitectura virreinal hispanoamericana constituiría un factor de diferenciación entre las regiones arquitectónicas virreinales, habría que concluir también que la arquitectura virreinal de Lima durante el siglo XVII, sobre la que en ningún modo influyó ese presunto factor diferenciador, constituyó una escuela regional diferenciada respecto de aquellas otras regiones arquitectónicas en las que el factor de los religiosos europeos no ibéricos estuvo activo. Resulta pues, que la especificidad de la arquitectura virreinal limeña durante el siglo XVII, al menos, no se configuró por las transmisiones europeas no ibéricas externas; sino por el trabajo profesional de los alarifes radicados en Lima y de procedencia distinta de la europea no ibérica. No es el caso de reiterar ahora que lo mismo ocurrió en otras arquitecturas virreinales peruanas, como la del Cuzco, la de Cajamarca, la de Arequipa, la del Collao, además de los otros núcleos menores. Creemos que es totalmente inútil buscar transmisiones externas de aportes europeos no ibéricos para interpretar, por ejemplo, las portadas puneñas de Lampa, Asillo y Ayaviri fabricadas bajo el mecenazgo del obispo don Manuel de Mollinedo y Angulo.

$\mathrm{El}$ resultado de aplicar la misma interpretación historiográfica homogénea a la múltiple y diferenciada arquitectura virreinal hispanoamericana, que además está condicionada por una innegable asincronía en su desarrollo histórico, no puede ser otro que el de una supercialidad especulativa que no explica nada en concreto, como sucede con la tesis europeísta aplicada a la arquitectura virreinal de Lima durante el siglo XVII.

La historiografía hispanista tampoco puede prescindir de la presuposición de las transmisiones externas realizadas por artífices cuya formación profesional procedería de la arquitectura española, especialmente la de Sevilla por donde embarcaban todos los pasajeros que venían a las Indias. Tal presuposición puede ser explícita o implícita; pero no por eso menos necesaria, a la tesis hispanista. Naturalmente que la determinación de los portadores personales de las presuntas transmisiones externas hispánicas está limitada en lo que atañe a sus defensores por la parquedad e inseguridad de las fuentes documentales usuales, que eran las conocidas hasta 1950. También ahora limitamos el análisis de la tesis hispanista a la arquitectura virreinal limeña durante el siglo XVII; dejando de lado lo que hubiera sucedido en otras regiones arquitectónicas hispanoamericanas e incluso peruanas.

En la ponencia al Simposio de Roma sobre el barroco latinoamericano celebrado en 1980, el historiador Bernales Ballesteros trató de precisar los nombres 
de algunos alarifes y ensambladores que trabajaron en Lima; pero no logró aducir otros nombres que los usuales de Juan Martínez de Arrona, Pedro de Noguera, Luis Ortiz de Vargas y Asencio de Salas entre los ensambladores; y los de Fray Diego Maroto, Manuel de Escobar, y Diego Pérez de Guzmán entre los alarifes ${ }^{13}$. Tratando de precisar algo más su escueta relación, escribía Bernales: "Nada sabemos de Pavía, de Fray Cristóbal Caballero, o de Constantino de Vasconcelos, pero es de suponer que todos debieron pasar por Sevilla para embarcar a las Indias y tal vez conocer el arte de Cano y de los Ribas" ${ }^{14}$. Anotemos, por lo pronto, que el tal Carlos Pavía es un personaje imaginario fabricado indocumentalmente por Vargas Ugarte; que Fray Cristóbal Caballero nació en Lima y nunca pisó el suelo de Sevilla; y que el acaudalado hombre de negocios don Constantino de Vasconcelos dibujó los planos para la iglesia de San Francisco de Lima, pero nunca ejerció el arte de la construcción en Lima como alarife; y que el limeño Diego Pérez de Guzmán, modesto oficial de albañil fue asentado por su padre el día 8 de enero de 1659 como aprendiz del oficio de albañilería con el alarife Francisco Cano Melgarejo, por el tiempo de tres años ${ }^{15}$, de tal manera que tampoco procedía de España ni conoció la arquitectura sevillana.

De vez en cuando reaparece la tesis de Bonet Correa acerca de la influencia de los conventos gallegos sobre la arquitectura limeña del siglo XVII ${ }^{16}$, que habría repercutido principalmente sobre la iglesia de San Francisco. De esta tesis se hace eco también Bernales ${ }^{17}$. Para que la tesis de las transmisiones externas procedentes de los conventos gallegos alcance alguna verosimilitud histórica, y no permanezca en la región de las meras suposiciones ideológicas, haría falta que se completara con la indicación de los alarifes concretos con nombres y apellidos que aportaron esas presuntas transmisiones externas. Desde luego, cuando el comisario general franciscano Fray Luis de Cervela, natural de Galicia, llegó a Lima ya estaba diseñada desde más de una década antes la iglesia de San Francisco y estaba en uso una parte importante de la construcción.

No puede soslayarse el hecho histórico de la afluencia a Lima de alarifes españoles de nacimiento y de formación profesional que trabajaron en la ciudad durante el siglo XVI y el siglo XVII. Hay que precisar, sin embargo, cuanto tiempo duró esta afluencia de alarifes y cual fue su influencia efectiva en el desarrollo de la arquitectura limeña. La afluencia de los alarifes españoles fue predominante en las primeras generaciones antes mencionadas; pero no aparecen

13. J. BERNALES BALLESTEROS, Portadas y retablos en Lima durante los siglos XVII y XVIII, en Simposio Inter. sul barocco lat., Roma, 1982, t. I, págs. 503-537.

14. Ibid., pág. 530.

15. A.G.N., escribano Gregorio de HERRERA, 1659, protocolo 846, folio 4.

16. A. BONET CORREA, La arquitectura en Galicia durante el siglo XVII, Madrid, 1966.

17. J. BERNALES, op. cit., pág. 531. 
figuras muy destacadas por su formación renacentista moderna, excepto el caso de Francisco Becerra. A partir de la generación que se inició en Lima hacia 1640 , se advierte la presencia creciente de alarifes de procedencia peruana. Señalemos algunos casos documentalmente comprobados. El alarife Juan de Mansilla era hijo de Clemente de Mansilla de trayectoria conocida en Lima, y se inició en la profesión como sustituto de su padre difunto en el cuidado de las cañerías de la ciudad: todo hace suponer que había nacido en Lima, y por supuesto su formación profesional es totalmente limeña. El dominico Fray Diego Maroto nació en el Norte del Perú, posiblemente en la ciudad de Trujillo; no conoció personalmente la arquitectura de España donde nunca estuvo; y su formación profesional fue peruana por completo. El alarife Domingo Alonso declaró que era natural de la feligresía de San Vicente en la ciudad de Oporto en Portugal ${ }^{18}$; no consta que trabajara como albañil en España antes de su venida al Perú; realizó en Lima algunas obras importantes diseñadas por Fray Diego Maroto y bajo la dirección de este maestro mayor de fábricas dominico.

Declaró Francisco Cano Melgarejo que había nacido en el Valle de Conchucos en Ancash 19; de tal modo que no tuvo ninguna formación ni conocimiento de la arquitectura española: en aquellos tiempos no se viajaba desde el Perú a la Metrópoli para aprender un oficio como el de albañilería.

Leemos en el testamento de Manuel de Escobar que había nacido en el pueblo de Gorgor, provincia de Cajatambo; y tampoco salió de Lima durante su vida profesional activa ni tuvo aprendizaje europeo.

El ayudante de ingeniero Pedro Asencio afirmaba el 3 de julio de 1685 al otorgar la dote de su hija que había nacido en el puerto del Callao ${ }^{20}$.

No tengo documentación acerca del lugar de nacimiento del alarife Francisco de Sierra; pero consta documentalmente que se asentó como aprendiz del oficio de albañil el día 15 de mayo de 1666 en las obras del Convento de San Francisco ${ }^{21}$; tampoco conoció la arquitectura española.

Diego de la Gama se declaraba "mulato libre", y Diego de Mondragón decía en su testamento que había nacido en el Callao, y que era hermano de Juan de Egoaguirre: su formación como alarife era, pues, exclusivamente limeña.

Las anotaciones precedentes condicionan en alguna medida la vigencia de la tesis historiográfica hispanista. Por lo pronto, es un hecho objetivo la coexistencia durante el mismo período de la segunda mitad del siglo XVII entre dos procesos: de un lado, la presencia creciente y decisiva a partir de la generación

18. A.G.N., escribano Gaspar de MONZON, 1669-1670, protocolo 1158, folio 3.423 vta. Poder para testar de fecha 13 de diciembre de 1669.

19. A.G.N., escribano Gregorio de HERRERA, 1655-1656, protocolo, 845, folio 305 .

20. A.G.N., escribano Pedro PÉREZ LANDERO, 1685, protocolo 1.183, folio 1.008.

21. A.G.N., escribano Nicolás GARCÍA, 1666, protocolo 706, folio 677 vta. 
de alarifes iniciada en 1640 de algunos maestros de albañilería que habían adquirido su formación profesional exclusivamente en el Perú, sin haber estado nunca en España; de otro lado, la diferenciación específica de la arquitectura virreinal limeña manifestada en los diseños para las portadas-retablo y las no-retablo, las modalidades de expansión volumétrica en las portadas, el empleo de componentes peculiares en las portadas como las pilastras con modillones, y la corpulencia externa de las iglesias. No se han encontrado antecedentes claros en la arquitectura española que muestren semejanzas constatables con las peculiaridades de la arquitectura limeña. Pero esta última no apareció por sí sola y anónimamente; sino que fue creada por alarifes de formación peruana. Las numerosas e importantes obras ejecutadas por Fray Diego Maroto y Manuel de Escobar no pueden ser explicadas sin más como arquitectura provincial española.

Han recurrido algunos historiógrafos al fácil expediente de negar a los alarifes virreinales el pleno ejercicio de su libertad creadora, que suponen haber estado restringida por las autoridades eclesiásticas; como si de este modo fortalecieran las tesis de las transmisiones externas europeas: las españolas y las no ibéricas. Se trata, en realidad, de una solución aparente porque, lejos de resolver el problema, crea un vacío interpretativo que nada logra llenar. Esta supuesta falta de creatividad afectaría a las personas; pero deja incólume la especificidad de la arquitectura limeña de la segunda mitad del siglo XVII como un hecho evidente que se resiste a ser anulado. Si no crearon esta arquitectura específica los alarifes limeños con el pleno empeño de su libertad creadora, ¿qué otras personas entendidas en el arte de la arquitectura pudieron inspirar los caracteres que configuran la originalidad de esta escuela regional? ¡Dejemos tranquilos a los eclesiásticos, que harto trabajo tenían en acopiar los recursos económicos para financiar las obras que encomendaron a los alarifes!

\section{RELACIÓN DE LOS ALARIFES DE LA CIUDAD}

Nota: se han tomado los datos de los Libros de Cabildos de Lima según los originales existentes en el Archivo Histórico de la Municipalidad de Lima (A.H .M.L.). La edición de los primeros Libros de Cabildos sigue numeración distinta que los originales del A.H.M.L. 


\begin{tabular}{|c|c|c|c|c|}
\hline Libro & Año & Folio & Fecha & A L A R IFES \\
\hline 12 & 1600 & $252 \mathrm{v}$ & $13-\mathrm{I}$ & Francisco BECERRA - Pedro FALCÓN \\
\hline$(1597)$ & 1601 & $292 \mathrm{v}$ & $12-\mathrm{I}$ & Pedro FALCÓN - Andrés de ESPINOSA \\
\hline 13 & 1602 & $5 v$ & 4-I & Francisco BECERRA - PEDRO FALCÓN \\
\hline \multirow[t]{3}{*}{$(1602)$} & 1603 & 131 & 13 & Pedro FALCÓN - Andrés de ESPINOSA \\
\hline & 1604 & 265 & 9-I & Cristóbal GÓMEZ - Alonso de ARENAS \\
\hline & 1605 & 403 & $10-\mathrm{I}$ & Cristóbal GÓMEZ - Francisco MORALES \\
\hline 14 & 1606 & 3 & 23-I & Alonso de MORALES - Juan del CERRO \\
\hline \multirow[t]{3}{*}{$(1606)$} & 1607 & 135 & $8-\mathrm{I}$ & Juan del CERRO - Cristóbal GÓMEZ \\
\hline & 1608 & 233 & 21-I & Juan del CERRO - Andrés de ESPINOSA \\
\hline & 1609 & $326 v$ & $5-\mathrm{I}$ & Juan del CERRO - Cristóbal GÓMEZ \\
\hline \multirow[t]{2}{*}{$\begin{array}{c}15 \\
(1610)\end{array}$} & 1610 & $7 v$ & 4-I & $\begin{array}{l}\text { Francisco VÁZQUEZ - Diego GUILLÉN } \\
\text { Antonio MAYORDOMO - Pedro } \\
\text { BLASCO }\end{array}$ \\
\hline & 1611 & 138 & 7-I & $\begin{array}{l}\text { Juan PÉREZ - Pedro BLASCO - Juan de } \\
\text { CERRO - Diego GUILLÉN }\end{array}$ \\
\hline \multirow{4}{*}{$\begin{array}{c}16 \\
(1612)\end{array}$} & 1612 & $15 v$ & $18-\mathrm{I}$ & Pedro VELASCO - Diego GUILLÉN \\
\hline & 1613 & - & - & $\begin{array}{l}\text { Francisco VÁZQUEZ DEL CASTILLO } \\
\text { Diego GUILLÉN (1) }\end{array}$ \\
\hline & 1614 & 216 & $3-I$ & $\begin{array}{l}\text { Francisco VÁZQUEZ DEL CASTILLO } \\
\text { Diego GUILLÉN }\end{array}$ \\
\hline & 1615 & $347 v$ & $2-I$ & $\begin{array}{l}\text { Francisco VÁZQUEZ DEL CASTILLO } \\
\text { Diego GUILLÉN }\end{array}$ \\
\hline \multirow[t]{5}{*}{$\begin{array}{c}17 \\
(1616)\end{array}$} & 1616 & 7 & 4-I & $\begin{array}{l}\text { Francisco VÁZQUEZ DEL CASTILLO } \\
\text { Andrés de ESPINOSA }\end{array}$ \\
\hline & 1617 & $76 v$ & 2-I & $\begin{array}{l}\text { Francisco VÁZQUEZ DEL CASTILLO } \\
\text { Diego GUILLÉN }\end{array}$ \\
\hline & 1618 & 145 & $5-\mathrm{I}$ & $\begin{array}{l}\text { Francisco VÁZQUEZ DEL CASTILLO } \\
\text { Francisco MORALES }\end{array}$ \\
\hline & 1619 & $220 v$ & 4-I & $\begin{array}{l}\text { Clemente de MANSILLA - Francisco } \\
\text { MORALES }\end{array}$ \\
\hline & 1620 & $297 v$ & 4-I & $\begin{array}{l}\text { Clemente de MANSILLA - Francisco } \\
\text { MORALES }\end{array}$ \\
\hline \multirow{4}{*}{$\begin{array}{c}18 \\
(1621)\end{array}$} & 1621 & 8 & 8-I & Alonso de ARENAS - Diego GULLÉN \\
\hline & 1622 & 103 & 4-I & $\begin{array}{l}\text { Alonso de ARENAS - Domingo CABE } \\
\text { ZAS }\end{array}$ \\
\hline & 1623 & 206 & $5-\mathrm{I}$ & $\begin{array}{l}\text { Domigo CABEZAS - Antonio MAYOR - } \\
\text { DOMO }\end{array}$ \\
\hline & 1624 & $327 v$ & 8-I & $\begin{array}{l}\text { Clemente de MANSILLA - Domingo CA } \\
\text { BEZAS }\end{array}$ \\
\hline
\end{tabular}

(1) Está roto el papel, pero estos alarifes fueron nombrados en 1614, porque "lo fueron el año pasado". Apoyados en esta anotación se les ha incluido como alarifes del año 1613. 


\begin{tabular}{|c|c|c|c|c|}
\hline Libro & Año & Folio & Fecha & A L A R IFES \\
\hline \multirow[t]{3}{*}{$\begin{array}{c}19 \\
(1625)\end{array}$} & 1625 & 7 & $3-\mathrm{I}$ & $\begin{array}{l}\text { Clemente de MANSILLA - Domingo CA- } \\
\text { BEZAS }\end{array}$ \\
\hline & 1626 & 124 & 2-I & $\begin{array}{l}\text { Clemente de MANSILLA - Antonio MA- } \\
\text { YORDOMO }\end{array}$ \\
\hline & 1627 & $223 v$ & $4-\mathrm{I}$ & $\begin{array}{l}\text { Clemente de MANSILLA - Joseph de la } \\
\text { SIDA }\end{array}$ \\
\hline \multirow[t]{3}{*}{$\begin{array}{c}20 \\
(1628)\end{array}$} & 1628 & $7 v-8$ & 3-I & $\begin{array}{l}\text { Clemente de MANSILLA - Domingo CA- } \\
\text { BEZAS }\end{array}$ \\
\hline & 1629 & 93 & $2-\mathrm{I}$ & $\begin{array}{l}\text { Clemente de MANSILLA - Domingo CA- } \\
\text { BEZAS }\end{array}$ \\
\hline & 1630 & $173 v$ & 2-I & $\begin{array}{l}\text { Clemente de MANSILLA - Antonio MA- } \\
\text { YORDOMO }\end{array}$ \\
\hline \multirow{3}{*}{$\begin{array}{c}21 \\
(1631)\end{array}$} & 1631 & 35 & 3-4-I & Joseph de la SIDA - Adrián TROCHE \\
\hline & 1632 & $111 \mathrm{v}$ & 2-I & $\begin{array}{l}\text { Clemente de MANSILLA - Antonio MA- } \\
\text { YORDOMO }\end{array}$ \\
\hline & 1633 & 203 & $3-\mathrm{I}$ & $\begin{array}{l}\text { Clemente de MANSILLA - Antonio MA- } \\
\text { YORDOMO }\end{array}$ \\
\hline \multirow[t]{4}{*}{$\begin{array}{c}22 \\
(1634)\end{array}$} & 1634 & 6 & $2-\mathrm{I}$ & $\begin{array}{l}\text { Joseph de la SIDA - Clemente de MANSI- } \\
\text { LLA }\end{array}$ \\
\hline & 1635 & 121 & $2-\mathrm{I}$ & $\begin{array}{l}\text { Antonio MAYORDOMO - Luis FER- } \\
\text { NÁNDEZ LOZANO }\end{array}$ \\
\hline & 1636 & 196 & $2-\mathrm{I}$ & Joseph de la SIDA - Adrián TROCHE \\
\hline & 1637 & 266 & $2-\mathrm{I}$ & $\begin{array}{l}\text { Francisco FAJARDO - Antonio MAYOR- } \\
\text { DOMO }\end{array}$ \\
\hline \multicolumn{5}{|c|}{$\begin{array}{l}1638 \text { Faltan las hojas del libro } \\
1639 \text { Faltan las hojas del libro }\end{array}$} \\
\hline \multirow[t]{5}{*}{$\begin{array}{c}23 \\
(1639)\end{array}$} & 1640 & $55 \mathrm{v}$ & 3-I & $\begin{array}{l}\text { Francisco FAJARDO - Antonio MAYOR- } \\
\text { DOMO }\end{array}$ \\
\hline & 1641 & $148 v$ & 2-I & $\begin{array}{l}\text { Francisco FAJARDO - Juan de MANSI- } \\
\text { LLA }\end{array}$ \\
\hline & 1642 & $218 v$ & $2-I$ & $\begin{array}{l}\text { Francisco FAJARDO - Juan de MANSI- } \\
\text { LLA }\end{array}$ \\
\hline & 1643 & $282 \mathrm{v}$ & $2-I$ & $\begin{array}{l}\text { Francisco FAJARDO - Juan de MANSI- } \\
\text { LLA }\end{array}$ \\
\hline & 1644 & $340 \mathrm{v}$ & $2-I$ & $\begin{array}{l}\text { Francisco FAJARDO - Pedro MIGUEL - } \\
\text { Juan de MANSILLA }\end{array}$ \\
\hline \multirow[t]{3}{*}{$\begin{array}{c}24 \\
(1644)\end{array}$} & 1645 & 11 & $3-I$ & $\begin{array}{l}\text { Juan de MANSILLA - Pedro MIGUEL - } \\
\text { Pedro de NOGUERA }\end{array}$ \\
\hline & 1646 & $71 \mathrm{v}$ & 2-I & $\begin{array}{l}\text { Juan de MANSILLA - Pedro MIGUEL - } \\
\text { Pedro de NOGUERA }\end{array}$ \\
\hline & 1647 & $134 \mathrm{v}$ & $2-I$ & $\begin{array}{l}\text { Juan de MANSILLA - Pedro MIGUEL - } \\
\text { Pedro de NOGUERA - Pedro BENÍ- } \\
\text { TEZ }\end{array}$ \\
\hline
\end{tabular}




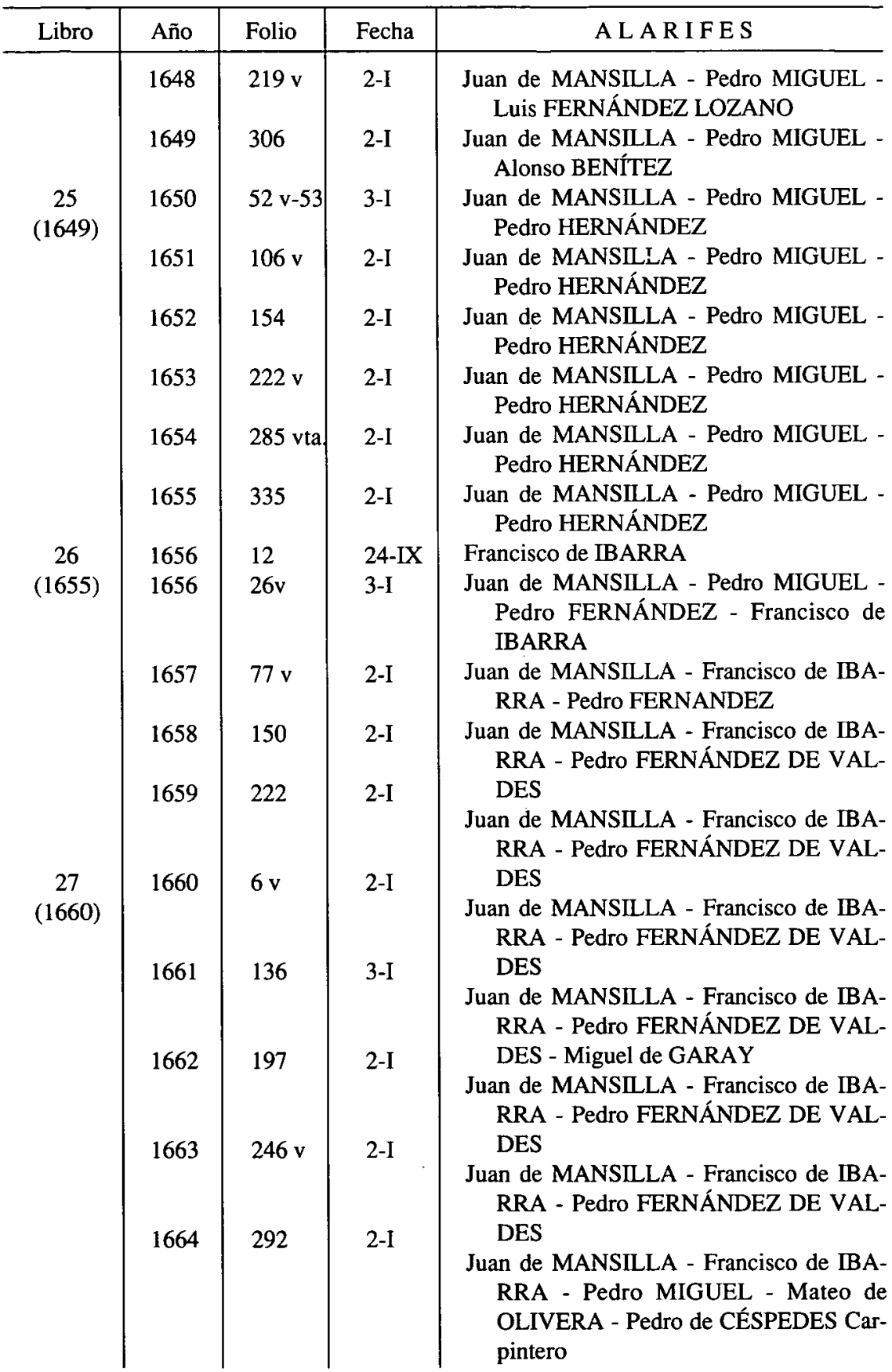




\begin{tabular}{|c|c|c|c|c|}
\hline Libro & Año & Folio & Fecha & A L A R IFES \\
\hline \multirow[t]{5}{*}{$\begin{array}{c}28 \\
(1664)\end{array}$} & 1665 & 19 & $2-\mathrm{I}$ & $\begin{array}{l}\text { Juan de MANSILLA - Francisco de IBA- } \\
\text { RRA - Pedro FERNANDEZ DE VAL- } \\
\text { DES - Pedro de CÉSPEDES Carpintero }\end{array}$ \\
\hline & 1666 & 52 & $2-I$ & $\begin{array}{l}\text { Domingo ALONSO - Francisco de IBA- } \\
\text { RRA - Pedro FERNÁNDEZ DE VAL- } \\
\text { DÉS - Pedro de CÉSPEDES Carpintero }\end{array}$ \\
\hline & 1667 & 94 & $3-I$ & $\begin{array}{l}\text { Domingo ALONSO - Francisco de IBA- } \\
\text { RRA - Pedro FERNÁNDEZ DE VAL- } \\
\text { DÉS - Pedro de CÉSPEDES carpintero }\end{array}$ \\
\hline & 1668 & $136 \mathrm{v}$ & $2-I$ & $\begin{array}{l}\text { Domingo ALONSO - Francisco de IBA- } \\
\text { RRA - Pedro FERNÁNDEZ DE VAL- } \\
\text { DÉS - Pedro de CÉSPEDES carpintero }\end{array}$ \\
\hline & 1669 & $197 v$ & $2-1$ & $\begin{array}{l}\text { Domingo ALONSO - Francisco de IBA- } \\
\text { RRA - Pedro FERNÁNDEZ DE VAL- } \\
\text { DÉS - Pedro CÉSPEDES carpintero - } \\
\text { Pedro MIGUEL }\end{array}$ \\
\hline \multirow[t]{6}{*}{$\begin{array}{c}29 \\
(1670)\end{array}$} & 1670 & 5 & 2-I & $\begin{array}{l}\text { Francisco de IBARRA - Pedro FERNÁN- } \\
\text { DEZ DE VALDÉS - Francisco MEL- } \\
\text { GAREJO - Pedro de CÉSPEDES car- } \\
\text { pintero }\end{array}$ \\
\hline & 1671 & $56 v$ & $2-I$ & $\begin{array}{c}\text { Francisco de IBARRA - Pedro FERNÁN- } \\
\text { DEZ DE VALDÉS - Francisco MEL- } \\
\text { GAREJO - Juan de EGOAGUIRRE }\end{array}$ \\
\hline & 1672 & $91 \mathrm{v}$ & 2-I & $\begin{array}{l}\text { Francisco de IBARRA - Pedro FERNÁN- } \\
\text { DEZ DE VALDÉS - Francisco MEL- } \\
\text { GAREJO - Juan de EGOAGUIRRE }\end{array}$ \\
\hline & 1673 & 138 & 2-I & $\begin{array}{l}\text { Francisco de IBARRA - Pedro FERNÁN- } \\
\text { DEZ DE VALDÉS - Francisco CANO } \\
\text { MELGAREJO - Juan de EGOAGUI- } \\
\text { RRE }\end{array}$ \\
\hline & 1674 & $197 \mathrm{v}$ & 2-I & $\begin{array}{l}\text { Manuel de ESCOBAR - FRANCISCO de } \\
\text { IBARRA - Pedro FERNÁNDEZ DE } \\
\text { VALDÉS - Francisco CANO MELGA- } \\
\text { REJO - Juan de EGOAGUIRRE }\end{array}$ \\
\hline & 1675 & 268 & 2-I & $\begin{array}{l}\text { Manuel de ESCOBAR - Francisco de } \\
\text { IBARRA - Pedro FERNÁNDEZ DE } \\
\text { VALDÉS - Francisco CANO MELGA- } \\
\text { REJO - Juan de EGOAGUIRRE - Pe- } \\
\text { dro de ASENCIO }\end{array}$ \\
\hline $\begin{array}{c}30 \\
(1676)\end{array}$ & 1676 & 5 & 2-I & $\begin{array}{l}\text { Francisco de IBARRA - Pedro FERNÁN- } \\
\text { DEZ DE VALDÉS - Francisco CANO } \\
\text { MELGAREJO }\end{array}$ \\
\hline
\end{tabular}




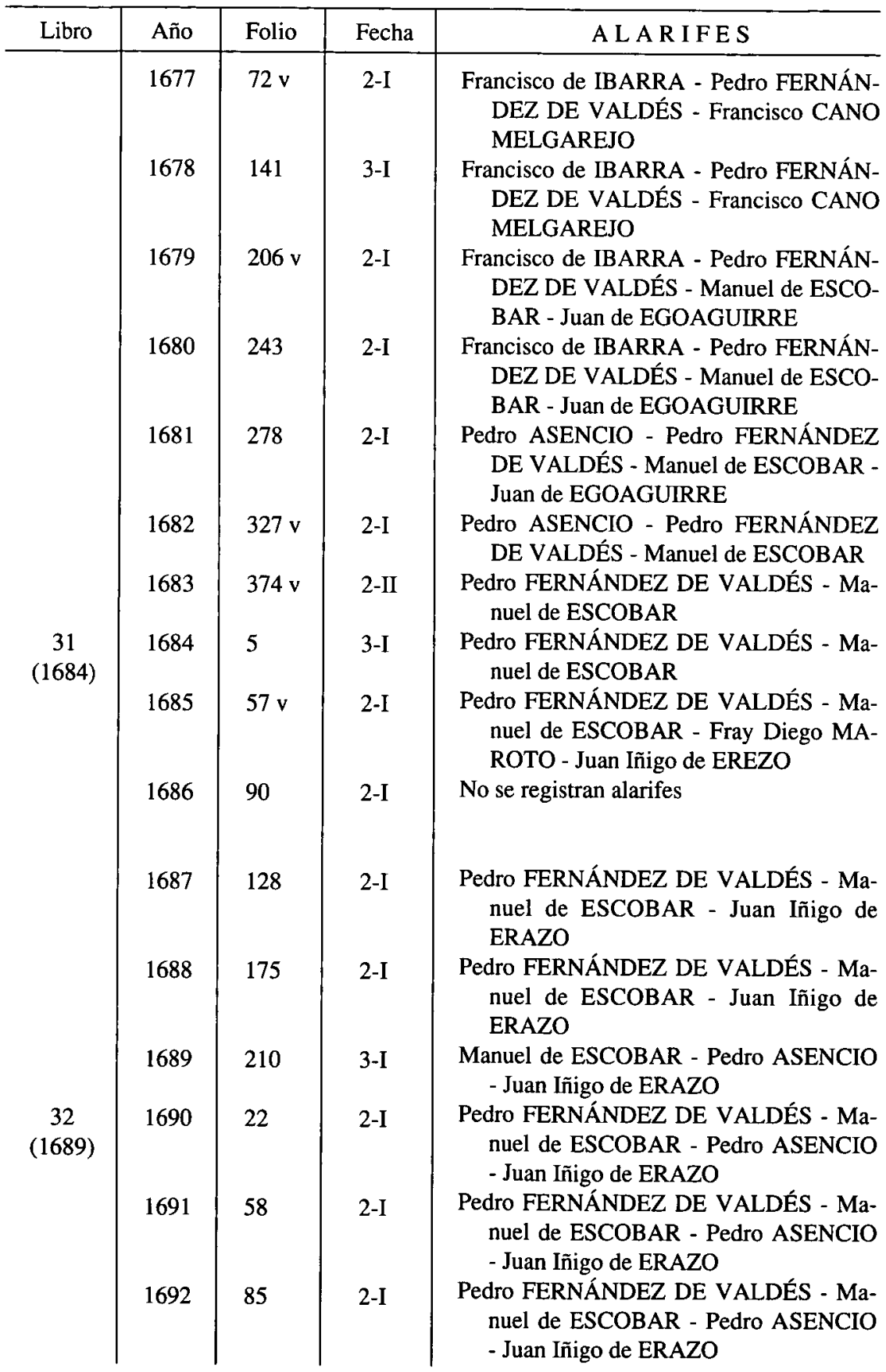




\begin{tabular}{|c|c|c|c|c|}
\hline Libro & Año & Folio & Fecha & A L A R IFES \\
\hline \multirow{9}{*}{$\begin{array}{c}33 \\
(1696)\end{array}$} & 1693 & $111 \mathrm{v}$ & $2-I$ & $\begin{array}{l}\text { Juan Iñigo de ERAZO - Manuel de ESCO- } \\
\text { BAR - Juan VELO }\end{array}$ \\
\hline & 1694 & 125 & $2-\mathrm{I}$ & $\begin{array}{l}\text { Pedro FERNÁNDEZ DE VALDÉS - Juan } \\
\text { Iñigo de ERAZO - Manuel de ESCO- } \\
\text { BAR - Juan de EGOAGUIRRE - Juan } \\
\text { VELO - Francisco JIMÉNEZ - Antonio } \\
\text { NOLETE - Diego de SEDILLO }\end{array}$ \\
\hline & 1695 & $138 v$ & $2-I$ & $\begin{array}{l}\text { Pedro FERNÁNDEZ DE VALDÉS - Alo- } \\
\text { nso SEDILLO - Pedro ASENCIO - Ma- } \\
\text { nuel de ESCOBAR - Juan Iñigo de } \\
\text { ERAZO }\end{array}$ \\
\hline & 1696 & 6 & 2-I & $\begin{array}{l}\text { Pedro FERNÁNDEZ DE VALDÉS - Juan } \\
\text { Iñigo de ERAZO }\end{array}$ \\
\hline & 1697 & 32 & $2-I$ & $\begin{array}{l}\text { Pedro FERNÁNDEZ DE VALDÉS - Pe- } \\
\text { dro ASENCIO - Juan Iñigo de ERAZO }\end{array}$ \\
\hline & 1698 & 65 & 2-I & $\begin{array}{l}\text { Pedro FERNÁNDEZ DE VALDÉS - Pe- } \\
\text { dro ASENCIO - Juan Iñigo de ERAZO }\end{array}$ \\
\hline & 1699 & 87 & $2-I$ & $\begin{array}{l}\text { Pedro FERNÁNDEZ DE VALDÉS - Pe- } \\
\text { dro ASENCIO - Juan Iñigo de ERAZO }\end{array}$ \\
\hline & 1700 & $110 v$ & 2-I & $\begin{array}{l}\text { Pedro FERNÁNDEZ DE VALDÉS - Pe- } \\
\text { dro ASENCIO }\end{array}$ \\
\hline & 1701 & 137 & $2-\mathrm{I}$ & $\begin{array}{l}\text { Pedro FERNÁNDEZ DE VALDÉS - Pe- } \\
\text { dro ASENCIO }\end{array}$ \\
\hline
\end{tabular}

